\section{P53 The Potential Problem of Picky Eating: A Pilot Study Among University Students of Food a Nutrition}

So-Young Kim, PhD, sonyah@sch.ac.kr, Soonchunhyang University, 22 Soonchunhyang-ro, Asan,

Chungcheongnam-do, South Korea, 31538; Eunju Lee, PhD, Dae-gok Elementary School

Background: Nutritional imbalances among adults are currently being recognized, particularly among those in their early 20s. Previous studies suggest that this problem might be related to adult picky eating (PE) behaviors. It has been taken for granted that university students majoring in food and nutrition, as prospective nutrition professionals, have already developed well-balanced dietary habits. However, this predisposition seems to be no longer entirely valid.

Objective: This pilot study aimed to explore the potential problem of PE among university students majoring in food and nutrition.

Study Design, Setting, Participants: The study included a total of 87 South Korean students majoring in food and nutrition. The Self-Designed Food Bridge Program was applied to identify the underlying causes of PE and examine the possibility of overcoming it. The program included planning and practicing step-wise exposures to target foods that were the subject of PE.

Measurable Outcome/Analysis: Descriptive statistics were calculated, and distributive differences between the success and failure groups in the program were analyzed using a chi-square test.

Results: Vegetables were the most commonly disliked foods $(74.7 \%)$. About $46 \%$ of all students mentioned negative experiences as a reason for food dislikes. Almost half (45\%) of these negative experiences were due to external coercion: forced eating (30\%) and vomiting after forced eating (15\%). About $66 \%$ of the students achieved relatively positive results in overcoming PE. The proportion of failures tended to be higher when the reasons for food dislike included negative experiences.

Conclusions: The results imply that students majoring in food and nutrition can be subject to PE. Despite some limitations, this study is meaningful in that it raises concerns over the potential problem of PE and its treatment among prospective nutrition professionals. The study is also expected to serve as a basis for further research on adult PE. Funding: Soonchunhyang University.

\section{P54 Youth CAN: Cultivating Community Change Through Youth-Driven Health Initiatives}

Ana Altares, BS, Colorado State University; Dana Sobel, BA, Colorado State University; Savannah Hobbs, MEd, Colorado State University; Tracy Nelson, PhD, MPH, Colorado State University; Magdalena Serpa, MPH, MD, Colorado State University; Laura Bellows, PhD, MPH, RDN, laura.bellows@colostate.edu, Colorado State University, 1571 Campus Delivery, Fort Collins, CO, 80523-1571

Background: The Youth CAN (Change.Activity.Nutrition.) project engages and empowers adolescents to become agents of change for health within their community. Students become active researchers through youthled participatory action research (YPAR), an innovative approach to youth-driven community assessment and project development.

Objective: To engage low-income, urban youth to identify an issue; connect with community stakeholders; and propose, develop, and implement a community-based project to promote healthy eating and active living.

Study Design, Setting, Participants: Two cohorts of high school students were recruited to conduct community assessments; cohort $1(n=20)$ consisted of students from a neighborhood high school and cohort $2(n=30)$ included participants in a summer leadership program at a local, non-profit organization.

Measurable Outcome/Analysis: Youth shared their experiences through multiple mediums of YPAR: PhotoVoice (photography), Spoken Word (poetry), and Street Art (graffiti-style artwork). Project themes were compiled and used to facilitate discussions between youth and community stakeholders using the World Café method. Perceived barriers and facilitators to healthy eating and active living were explored and discussion outputs were synthesized into common themes to determine potential community-based projects.

Results: Students' projects were displayed in an exhibit to inspire dialogue for the World Café. PhotoVoice $(n=32)$, Spoken Word $(n=8)$, and Street Art $(n=10)$ projects portrayed the lived experiences of youth in their community. The World Café consisted of discussions driven by youth $(n=20)$ with input from community stakeholders $(n=20)$. Themes included addressing the current school lunch environment, implementing community gardens, and introducing composting at schools. Students are currently working with community stakeholders and researchers to design and implement a community project.

Conclusions: Youth empowerment is fundamental in building connections within the community and yielding community projects to promote health. Future research efforts should incorporate multiple applications of YPAR into nutrition education programs to engage a broader youth audience.

Funding: The Rockefeller Foundation.

\section{P55 Providing Nutrition Education to Refugees: Successful Strategies and Barriers to Success In Current Programs}

Jessica Gough, BS, Utah State University; Heidi Wengreen, PhD, RDN, heidi.wengreen@usu.edu, Utah State University, 8700 Old Main Hill, Logan, UT, 84322-8700; Habiba Nur, MS, Utah State University; Martha Archuleta, $P h D, R D N$, Utah State University

Background: Refugees face many changes in purchasing and preparing nutritious food for their families upon relocation. Nutrition education can be an important part of improving nutrition and health for refugees.

Objective: To survey current providers of refugee nutrition education in the United States about current program

Continued on page $S 42$ 


\section{P55 (continued)}

implementation, successful program strategies, program challenges, and future program needs.

Study Design, Setting, Participants: All program directors of Supplemental Nutrition Education Program Education (SNAP-Ed) and Expanded Food and Nutrition Education Program (EFNEP) programs in the US were invited to complete an online Qualtrics survey.

Measurable Outcome/Analysis: SPSS was used to run descriptive statistics on the quantitative variables; grounded theory was used to explore the qualitative data.

Results: Forty-one participants from 36 states responded to the survey. Thirteen directors from 12 states reported implementing no programs targeted at refugees in the past year. Twenty-eight directors from 24 states reported implementing at least 1 program targeted at refugees in the past year. The average number of programs reported by states that had at least 1 program was 4 . Directors ranked the efficacy of the programs they implemented from $0-100 \%$ effective. The average efficacy of programs was 75.8 (range 20 - 100; SD 17.6). Hands-on, skill-based learning such as gardening, cooking classes, grocery store tours, and tasting experiences emerged as a main theme of successful programs. Language and cultural issues including the need for translation in multiple languages and culturally sensitive curriculum emerged as main themes of challenges to successful programs.

Conclusions: Extension programs provide nutrition education to refugees in many states. Future programs aimed at helping refugees to healthfully adapt to their new food environments should provide culturally sensitive opportunities for skill-based learning.

Funding: Utah State University Extension.

\section{P56 "We are Suffering": Perceptions of Adults Living with HIV in Abeokuta, Nigeria on Their Food Intakes}

Temitope Kayode Bello, PhD, MPH, MS, BS, RDN, tk. bello@up.ac.za, University of Pretoria, South Africa, Room 8-10 Level 8 HW Snyman Building, Pretoria, Gauteng, South Africa, 27; Gerda Gericke, MS, BS, RDN, University of Pretoria, South Africa; Una MacIntyre, PhD, MS, BS, RDN, University of Pretoria, South Africa

Background: Nigeria is still one of the most affected countries in the world with the global burden of HIV/ AIDS. Presently, there seems no published research in Nigeria that explored perceptions of adults living with HIV (ALH) in Abeokuta, Nigeria on factors affecting their food intakes.

Objective: To explore perceptions of adults living with HIV (ALH) in Abeokuta, Nigeria on factors affecting their food intakes.

Study Design, Setting, Participants: Phenomelogical in-depth interview in a qualitative domain with 20 ALH in Abeokuta taking part in an exploratory study that aimed to develop, implement a theory guided nutrition education program (NEP) and to evaluate the program's impact on the quality of life (QoL), nutrition knowledge attitude and practices (KAP), and dietary quality (DQ) of ALH who attended the Federal Medical Center (FMC) and Ijaye State Hospital (ISH) in Abeokuta, Nigeria. Participants were interviewed in focus group discussions (FGDs) on their perception of their food intakes.

Measurable Outcome/Analysis: Thematic framework was used for the data analysis.

Results: Findings show that nutrition intervention was not part of the ongoing intervention program in Nigeria, and participants' direct quotes also confirmed that they received very limited nutrition supports from the government. The Nigerian government initiatives of proving highly active antiretroviral therapy (HAART) to relieve mortality rates associated with HIV, to improve health status and QoL were also perceived inadequate for positive living. Participants perceived one of the ways to manage common HIV/AIDS related symptoms, especially diarrhea, was by complete abstinence from vegetables intake. This suggested a need for NEP.

Conclusions: The results of this study indicated that an NEP tailored to the needs of ALH (such as guidelines on good nutrition with limited resources, planning a wellvaried meal, dealing with barriers to healthy eating, and tips on dietary diversity and adherence to HAART) may be needed to help slow disease progression of AIDS, leading to an improved QoL.

Funding: None.

\section{P57 Coalition-Based School Gardening and Nutrition Education through SNAP-Ed}

Diane Clement, MEd, University of Arkansas, Division of Agriculture, Cooperative Extension Service; Les Walz, MS, University of Arkansas, Division of Agriculture, Cooperative Extension Service; Katie Holland, MS, $R D$, University of Arkansas, Division of Agriculture, Cooperative Extension Service; Amy McClelland, MS, RD, amcclelland@uaex.edu, University of Arkansas, Division of Agriculture, Cooperative Extension Service, $2301 \mathrm{~S}$. University Avenue, Little Rock, AR, 72204; Sarah David, $M B A, M M$, University of Arkansas, Division of Agriculture, Cooperative Extension Service; Bryan Mader, DPH, MPH, CHES, University of Arkansas, Division of Agriculture, Cooperative Extension Service; Debie Head, EdD, $R D, L D$, $C D E$, University of Arkansas, Division of Agriculture, Cooperative Extension Service

Objective: To implement coalition-based gardening and nutrition education with tasting activities to increase willingness to eat fruits and vegetables to address youth obesity rates.

Use of Theory or Research: Studies show children are more likely to eat fruits and vegetables when they participate in growing and harvesting. Increased intake of fruits and vegetables has been shown to be associated with reduced risk of weight gain and overweight or obesity. A plan was created to use gardening and nutrition education with tasting activities to increase willingness to eat fruits and vegetables.

Target Audience: Students in SNAP-Ed eligible schools.

Continued on page $S 43$ 